\title{
Capacitação Competitiva da Indústria de Transformação de Plástico
}

A presente matéria elaborada pelos professores Afonso Fleury e Maria Tereza Fleury é o resultado de um importante estudo da cadeia produtiva dos polímeros no Brasil. São mostradas as características organizacionais das diversas cadeias do setor produtivo de plásticos, onde estão envolvidas formas inter e intra-nacionais de organização econômica, sendo avaliadas as estruturas que coordenam e controlam atividades econômicas geograficamente dispersas. A ABPol foi ouvida durante o processo de caracterização geral das cadeias produtivas onde discutiu-se quem é quem, quais mecanismos e imposições para participar de uma cadeia e quais as articulações internacionais. Dessa forma foi possível contribuir com a visualização do desempenho competitivo das empresas de plástico nas cadeias produtivas.

\section{Objetivo do Projeto}

O objetivo do projeto foi elaborar um diagnóstico do setor industrial de transformação de plásticos, para subsidiar o desenvolvimento de um programa de atuação com a finalidade de aumentar a produtividade e a competitividade do setor e das cadeias produtivas de que participa, otimizando os prováveis impactos da globalização produtiva.

\section{Abordagem do estudo e pressu- postos básicos}

A abordagem adotada para este estudo foi a da formação de cadeias produtivas.

A princípio, analisar a indústria de transformação de plástico a parir de uma perspectiva de cadeia não seria novidade, já que tecnicamente, os processos produtivos são interligados "em cascata". Mas, apesar do uso constante do termo cadeia, tanto as análises quanto as políticas industriais raramente se pautaram por essa abordagem. A segmentação tradicional que define como categorias: resinas, máquinas e transformadoras, que tem origem na estrutura sindical corporativista brasileira, é mais comumente encontrada e tem influenciado sobremaneira o comportamento dos diversos agentes econômicos.

A abordagem a partir de cadeias produtivas parte dos seguintes pressupostos (adaptado de Gerefii: 1996)

- a ênfase maior do estudo se volta para as características organizacionais das cadeias, com particular atenção para o papel desempenhado pelas diferentes formas de relação economica, não obstante se considere que as cadeias produtivas possam ser influenciadas por aspectos institucionais de origem local, nacional e internacional.

- por sua própria natureza, as cadeias produtivas envolvem formas inter e intra-nacionais de organização econômica, não obstante o espaço geográfico dessas cadeias seja variável (algumas são globais enquanto outras podem ser regionais).
- as cadeias produtivas têm estruturas de governança (governance) que coordenam e controlam atividades econômicas geograficamente dispersas.

A dinâmica competitiva das ca-

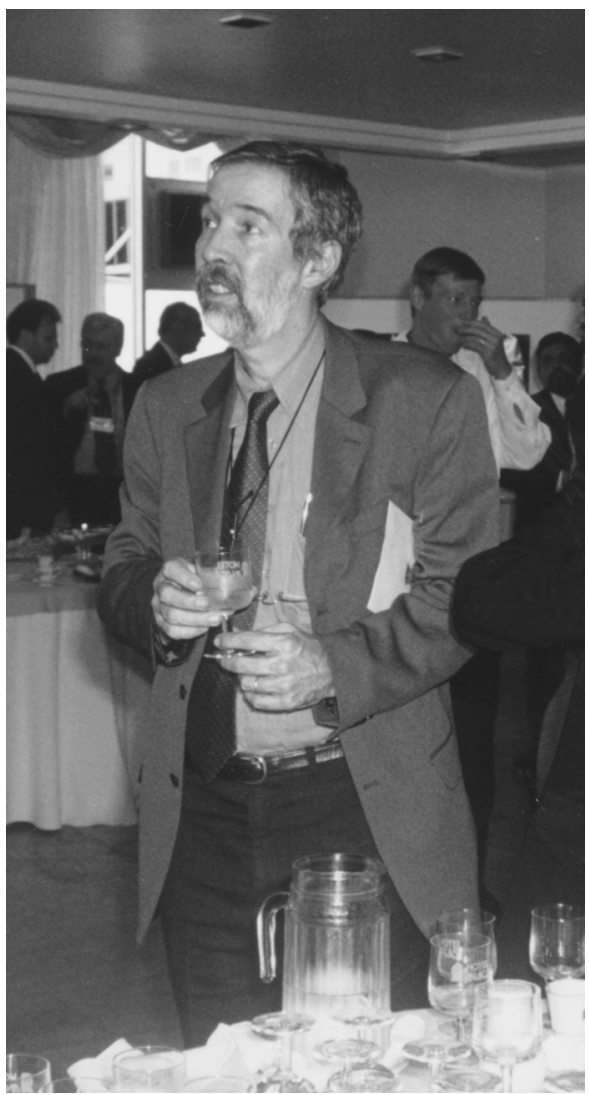

Prof. Afonso Fleury 
deias produtivas (e sua estrutura de governança) define requisitos aos quais devem atender aquelas empresas que pretendem delas participar. Para tanto, as empresas devem desenvolver capacitações (gerenciais, tecnológicas e operacionais). Do ponto de vista organizacional isso implica em que cada empresa identifique as funções críticas nas quais deve desenvolver competência diferenciada.

O estudo da indústria de transformação de plástico a partir d uma perspectiva de cadeias produtivas justifica-se na medida em que o acirramento da competição das indústrias a jusante (ou seja, entre as empresas que consomem produtos plásticos: automobilísticas, eletrônicas, alimentícias, etc.) e a montante (ou seja, as empresas de segunda geração fornecedoras de resinas) tem levado ao enfraquecimento das relações horizontais e intensificação do processo de alinhamento das empresas de transformação de plástico nas diferentes cadeias produtivas. A Figura 1 representa, esquematicamente, a cadeia de transformação de plástico.
Não são todas as empresas transformadoras de plásticos que estão se alinhando em cadeias produtivas, mas a abordagem a partir de cadeias produtivas permite aprender a dinâmica geral do setor.

Historicamente, as empresas de transformação de plástico eram especializadas no processo (injeção, extrusão, etc.), fornecendo de maneira relativamente indiscriminada para diferentes clientes e mercados. Pode-se afirmar que enquanto o mercado foi vendedor, as empresas escolhiam produtos de modo a maximizar a utilização da capacidade produtiva instalada.

Com o advento da abertura dos mercados e a intensificação da competição pelo processo de globalização, o mercado se tornou comprador, e grande parte das empresas precisaram passar a um estágio de focalização de atividades buscando identificar os seus core businesses e seus clientes/mercados. As condições para permanecer como participante de determinadas cadeias produtivas foram redefinidas, em geral, exigindo alta capacidade de produção e relativa

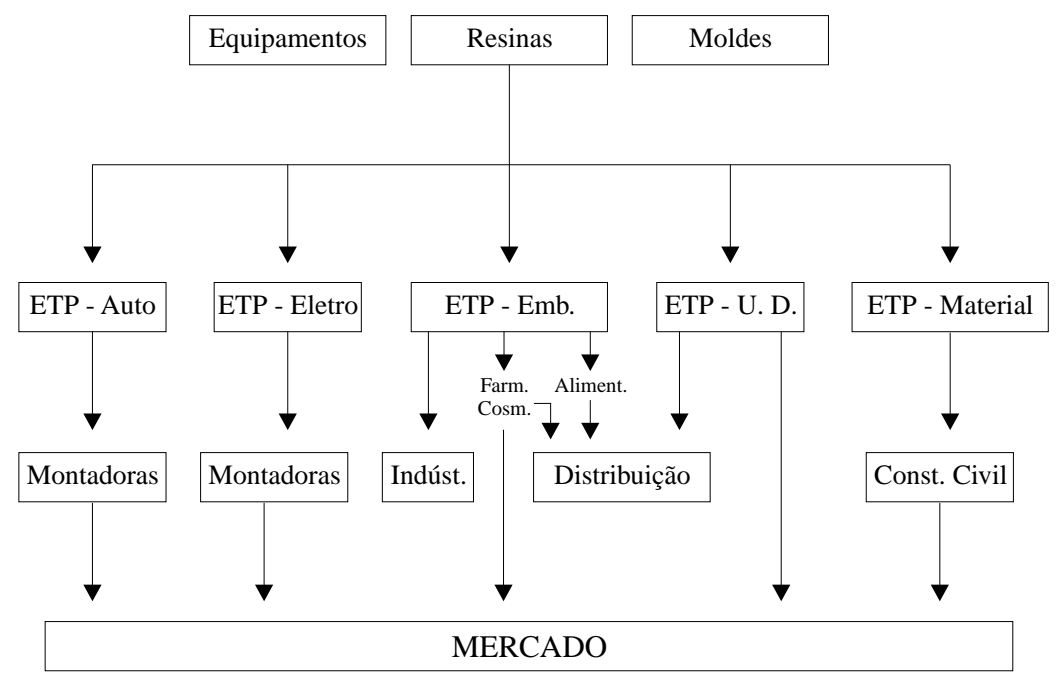

Obs.: ETP = Empresa Transformadora de Plásticos

Figura 1. Cadeia de transformação de plástico capacitação para desenvolvimento de produtos.

Assim, no caso da indústria brasileira de transformação de plástico observa-se atualmente grupos de empresas com diferentes características, dependendo de possível inserção em cadeia produtiva e da estratégia de mercado:

a) Há empresas de transformação de plástico que estão alinhadas ou procurando se alinhar em cadeias produtivas nas quais oelemento mais forteé aquele que faz a intermediação direta com o mercado. Usando a tipologia proposta por Gereffi (1994), encontramos dois tipos de cadia produtiva: as cadeias comandadas pelo produtor (producer driven commodity chains) e as cadeias comandadas pelo comprador (buyer driven commodity chains). Entre as primeiras estão a cadeia automobilística e a cadeia de eletroeletrônica; como exemplo do segundo tipo de cadeia o mais ilustrativo é o das redes de distribuição, como os supermercados.

Nesses casos, as empresas locais estão sendo "ensanduichadas", tendo a montante os produtores de resina, empresas de grande porte, ligadas aos grandes oligopólios internacionais ou ao sistema produtivo estatal, e a jusante grandes empresas transnacionais. Essas grandes empresas comandam cadeias que competem em termos de apropriação do valor agregado. Consequentemente, as empresas transformadoras de plástico estão sendo pressionadas pelos dois lados no sentido de reduzir preços, aumentar a qualidade e serem inovadoras.

b) Há um segundo tipo de empresas de transformação de plástico, exemplificado pela construção civil e utilidades domésticas, no qual a pressão a jusante é a "normal de 
mercado", o que permite uma atuação menos tensionada.

As considerações acima dizem respeito aos segmentos mais dinâmicos e avançados da indústria transformadora de plástico. O que torna importante diferenciar tais cadeias é que as suas estruturas de governance são peculiares. Ou seja, as relações de poder na cadeia assumem configurações específicas que precisam ser entendidas para que se possa formular programas e ações.

c) Há um grupo de pequenas e médias empresas que atendem às demandas de mercados locais, pulverizados, anônimos, com produtos que têm atributos de qualidade e preço definidos de acordo com tais realidades. O universo das empresas transformadoras de plástico é muito heterogêneo. Dada a versatilidade de aplicação e a facilidade de produção de artigos de plástico, há uma infinidade de nichos que justificam a existência de mais de 5.000 empresas transformadoras de plástico no país. Embora as estatísticas não sejam totalmente confiáveis, estima-se que mais do que 1.000 empresas entrem e saiam desse mercado a cada ano. Assim, há empresas que não estão diretamente envolvidas nas cadeias produtivas anteriormente citadas e que representam uma parcela significativa do total de empresas formalmente estabelecidas. Esse grupo de pequenas e médias empresas tem grande impacto na geração de emprego e renda. Artigos de papelaria e sacaria exemplificam bem esse tipo de produto e empresa.

d) Finalmente, há ainda um outro conjunto importante, constituído por empresas "informais" que, portanto, estão fora das estatísti- cas oficiais, mas cuja ação tem trazido repercussões significativas sobre o funcionamento da indústria em geral. Na medida em que trabalham em situação marginal, sem recolher impostos e utilizando relações precárias de trabalho, em mercados não regulamentados de produtos pouco sofisticados, essas empresas concorrem com as empresas formais com vantagens evidentes em custos e preços. Há estimativas de que as empresas informais respondem por cerca de 100.000 postos de trabalho.

\section{Metodologia e características das empresas pesquisadas}

Um primeiro diagnóstico da indústria brasileira de transformação de plástico foi elaborado a partir de pesquisa de campo que envolveu 18 empresas a montante e a jusante.

A partir de indicações dessas empresas, da análise de relatórios e de discussões com associações, foi montado um cadastro com aproximadamente 100 empresas de transformação de plástico. A amostra pesquisada neste projeto foi selecionada desse cadastro, utilizando-se como critérios de escolha: o tipo de cadeia produtiva, o tamanho e a localização geográfica.

É necessário registrar que algumas das empresas contatadas não possibilitaram o acesso dos pesquisadores em função do momento por que estavam passando: mudança de controle acionário ou crise financeira.

As empresas foram classificadas em quatro cadeias produtivas: a auto/eletro, a de embalagens, a de construção civil e a de utilidades domésticas.

Na prática, observou-se que o "alinhamento" das empresas nas cadeias não é perfeito. Isto reflete tanto a resistência das empresas em focalizarem a sua estratégia competitiva numa única cadeia, quanto a tática de migrar de uma cadeia para outra por não conseguir atender aos requisitos de competitividade da cadeia produtiva ou por não estar de acordo com o estilo e os critérios de governance.

As informações coletadas em cada empresa foram organizadas tendo em vista analisar o desempenho competitivo das cadeias produtivas a partir de seis aspectos.

\section{a. Características gerais da cadeia produtiva}

Neste item são apresentados os participantes da cadeia produtiva e sua evolução. Discute-se, em seguida as características gerais de governance: quem comanda a cadeia, quais são os requisitos impostos para as empresas que quiserem participar, quais são os mecanismos para coordenação da cadeia, se há uma articulação internacional e como isto afeta o comportamento das empresas.

\section{b. Análise dos indicadores de desempenho}

Para cada empresa foram calculados três indicadores de desempenho:

- receita por tonelada transformada

- receita por funcionário

- índice de ociosidade

O primeiro dá uma idéia do desempenho operacional da empresa em termos de agregação de valor, o segundo é o indicador de produtividade geral e o terceiro reflete a capacidade da empresa de vender e utilizar a sua capacidade produtiva. 
$\mathrm{Na}$ análise dos indicadores o mais relevante foi a dispersão dos valores, o que era indicativo dos diferenciais em termos de performance entre as empresas de transformação de plástico participantes e uma mesma cadeia produtiva e portanto sujeitas aos mesmos condicionamentos de desempenho.

\section{c. Características gerais do processo produtivo}

Neste item são apresentadas as informações que permitem um melhor entendimento dos aspectos ligados à operação de cada uma das cadeias produtivas.

O primeiro diz respeito ao tipo de transformação de plástico predominante: injeção, extrusão, etc. Em seguida procura-se identificar a característica do parque de máquinas existente nas empresas pertencentes à cadeia, em termos de idade, nível de automação e outros fatores. Finalmente procura-se trabalhar a questão dos moldes: importância, origem, posse, etc.

\section{d. Relações entre os participantes da cadeia produtiva}

Para avançar no entendimento da dinâmica das cadeias produtivas são analisadas as interfaces entre as empresas de transformação de plástico e os seus fornecedores e clientes.

Os aspectos analisados dizem respeito a cooperação e conflito, confiança e desconfiança, submissão ou autonomia, que são aspectos que vão influenciar a definição de estratégias, o modelo organizacional e as formas de produzir das empresas de transformação de plástico. A relação com os consumidores/clientes é a mais importante e, especialmente nos casos das cadeias auto/eletro e embala- gens, nas quais os clientes têm grande poder de barganha e definem as regras para o funcionamento de toda a cadeia produtiva, essa relação é determinante de estratégias e comportamentos.

A relação com os fornecedores de resina tem como fatores essenciais: a negociação de preços, a qualidade do produto fornecido e a confiabilidade na entrega. A importância de cada fator varia de acordo com a cadeia produtiva na qual opera a empresa transformadora. Quanto aos aspectos de inovação, isto está mais do campo de atuação das produtoras de resina, como já foi observado.

A relação com os fornecedores de equipamentos e de moldes foi trabalhada com duas preocupações. A primeira era a de entender a natureza e a intensidade das relações. Haveria fidelidade da transformadora no sentido de comprar sempre de um mesmo fabricante e interação constante através de trocas de informação sobre o desempenho dos equipamentos? Do outro lado, estariam os fabricantes de equipamentos e de moldes evoluindo de maneira a estar sempre atendendo às demandas das empresas de transformação? Esta dinâmica determina a capacidade de evolução conjunta do sistema na medida em que se sabe que o desenvolvimento da indústria de máquinas depende sobremaneira da qualidade da interação com o usuário. O segundo ponto, associado ao primeiro, é entender até que ponto os requisitos de competitividade impostos para a cadeia pressionam ou não as empresas de transformação de plástico a adquirirem equipamentos não disponíveis no país, através de importação.

\section{e. Fatores e funções críticas para a competitividade}

Neste item, parte-se para a análise mais detalhada da estratégia e da organização das empresas de transformação de plástico. Do ponto de vista de estratégia, pesquisou-se quais seriam os principais fatores de competitividade para as empresas (preço, qualidade, confiabilidade na entrega, inovação, ou outro) e como estariam priorizados. Perguntou-se também quais seriam, nas empresas, as funções organizacionais críticas para garantir o desempenho competitivo. Essas duas questões permitiram mapear os requisitos de competitividade na cadeia, tais como vistos pelos gestões das empresas de transformação de plástico e como eles organizam suas empresas para essa competição. $\mathrm{Na}$ medida em que também foram identificados os requisitos de competitividade na visão das empresas que comandam as cadeias produtivas, foi possível analisar até que ponto as empresas de transformação de plástico estão estrategicamente bem posicionadas e bem organizadas.

\section{f. Formação e gestão das compe- tências}

Após a caracterização dos aspectos de estratégia e organização, discute-se a gestão de recursos humanos, objetivando avaliar como estão criadas e desenvolvidas as competências necessárias para que as funções organizacionais críticas sejam adequadamente realizadas, de maneira a garantir a consecução das estratégias escolhidas. Neste sentido procura-se caracterizar o perfil dos recursos humanos alocados às funções críticas, em termos quantitativos (porcentagem do total de 
funcionários) e qualitativos (nível educacional, experiência). As funções organizacionais focalizadas foram: gerência, engenharia, comercial, ferramentaria, produção, assistência técnica e outras. Foram ainda analisados diferentes aspectos de gestão de recursos humanos para se identificar até que ponto as empresas estão investindo na melhoria de seus funcionários. Assim, foram colhidas informações sobre o sistema de remuneração adotado pelas empresas para entender se estas estão ou não buscando o envolvimento $\mathrm{e}$ o comprometimento dos funcioná- rio, condição básica para que possa haver aperfeiçoamento das pessoas e aprendizagem organizacional. Da mesma forma foram obtidas informações sobre investimentos em educação e treinamento.

Finalmente, foram colhidas informações sobre a aplicação de téc-

Quadro 2. Desempenho competitivo das empresas de transformação de plástico nas cadeias produtivas

\begin{tabular}{|c|c|c|c|c|c|}
\hline & Auto/eletro & Embalagens & $\begin{array}{l}\text { Unidades } \\
\text { Domésticas }\end{array}$ & Construção & $\begin{array}{c}\text { Fora da cadeia } \\
\text { Médias/pequenas }\end{array}$ \\
\hline $\begin{array}{l}\text { Modelo organiza- } \\
\text { cional atual }\end{array}$ & $\begin{array}{l}\text { Comandado pelas } \\
\text { montadoras e me- } \\
\text { gasuppliers; em- } \\
\text { presas locais sendo } \\
\text { gradualmente des- } \\
\text { locadas. }\end{array}$ & $\begin{array}{l}\text { Poucas empresas } \\
\text { locais capacitadas a } \\
\text { atuar nos moldes } \\
\text { pretendidos pelos } \\
\text { clientes; desajuste } \\
\text { entre demanda e } \\
\text { oferta em termos de } \\
\text { produtos e serviços. }\end{array}$ & $\begin{array}{l}\text { Poucas empresas } \\
\text { pequenas e médias } \\
\text { focadas nesse mer- } \\
\text { cado; funciona co- } \\
\text { mo buffer para em- } \\
\text { presas que atuam } \\
\text { em outras cadeias. }\end{array}$ & $\begin{array}{l}\text { Gradual concen- } \\
\text { tração emgrandes } \\
\text { empresas locais. }\end{array}$ & $\begin{array}{l}\text { Produzindo espe- } \\
\text { cialmente embala- } \\
\text { gens e utilidades- } \\
\text { domésticas }\end{array}$ \\
\hline $\begin{array}{l}\text { Requisitos de compe- } \\
\text { titividade na cadeia } \\
\text { produtiva }\end{array}$ & $\begin{array}{l}\text { domínio da tecno- } \\
\text { logia; saúde finan- } \\
\text { ceira; qualidade; en- } \\
\text { trega; preço inter- } \\
\text { nacional }\end{array}$ & $\begin{array}{l}\text { conhecer o merca- } \\
\text { do e desenvolver } \\
\text { sistemas de emba- } \\
\text { lagens; qualidade; } \\
\text { entrega; preço. }\end{array}$ & $\begin{array}{l}\text { design; qualidade; } \\
\text { preço. }\end{array}$ & $\begin{array}{l}\text { disponibilidade de } \\
\text { produtos padroni- } \\
\text { zados; preço; gra- } \\
\text { dual aumento da } \\
\text { importância da ino- } \\
\text { vação }\end{array}$ & $\begin{array}{l}\text { conhecimento de } \\
\text { mercados locais. }\end{array}$ \\
\hline $\begin{array}{l}\text { Fatores críticos de } \\
\text { sucesso das empresas }\end{array}$ & $\begin{array}{l}\text { capacitação tecno- } \\
\text { lógica; capacitação } \\
\text { para negociação. }\end{array}$ & $\begin{array}{l}\text { customer inti-macy; } \\
\text { prospecção de mer- } \\
\text { cados; desenvolvi- } \\
\text { mento de produ- } \\
\text { tos/sistemas. }\end{array}$ & $\begin{array}{l}\text { desenvolvimento de } \\
\text { produtos, proces- } \\
\text { sos e moldes; co- } \\
\text { mercialização. }\end{array}$ & $\begin{array}{l}\text { produção emescala } \\
\text { dentro de padrões } \\
\text { de qualidade; dis- } \\
\text { tribuição. }\end{array}$ & $\begin{array}{l}\text { rápida identifica- } \\
\text { ção de necessida- } \\
\text { des e ágil atendi- } \\
\text { mento. }\end{array}$ \\
\hline $\begin{array}{l}\text { Competências essen- } \\
\text { ciais das empresas }\end{array}$ & $\begin{array}{l}\text { tecnologia do plás- } \\
\text { tico; gestão da pro- } \\
\text { dução }\end{array}$ & $\begin{array}{l}\text { marketing; tecno- } \\
\text { logia de embala- } \\
\text { gens; engenharia de } \\
\text { aplicação }\end{array}$ & $\begin{array}{l}\text { design; engenharia } \\
\text { de processo. }\end{array}$ & $\begin{array}{l}\text { comercial e logís- } \\
\text { tica; operação efi- } \\
\text { ciente; gestão de } \\
\text { custos. }\end{array}$ & $\begin{array}{l}\text { monitoramento das } \\
\text { demandas e busca } \\
\text { de conhecimentos } \\
\text { para viabilizar pro- } \\
\text { dução. }\end{array}$ \\
\hline $\begin{array}{l}\text { Tendências na cadeia } \\
\text { produtiva }\end{array}$ & $\begin{array}{l}\text { comando total das } \\
\text { empresas estrangei- } \\
\text { ras; empresas locais } \\
\text { no terceiro nível de } \\
\text { fornecimento. }\end{array}$ & $\begin{array}{l}\text { gradual entrada de } \\
\text { empresas estran- } \\
\text { geiras, especialmen- } \\
\text { te articuladas a em- } \\
\text { presas de produtos } \\
\text { de consumo. }\end{array}$ & $\begin{array}{l}\text { provável entrada de } \\
\text { empresas estrangei- } \\
\text { ras, especialmente } \\
\text { se articuladas a re- } \\
\text { des de distribuição. }\end{array}$ & $\begin{array}{l}\text { concentração em } \\
\text { grandes empresas } \\
\text { locais; prováveis } \\
\text { associaçoes com es- } \\
\text { trangeiros para pro- } \\
\text { dutos novos. }\end{array}$ & $\begin{array}{l}\text { ameaças vêm de } \\
\text { possível expansão } \\
\text { das redes de distri- } \\
\text { buição e dos possí- } \\
\text { veis impactos sobre } \\
\text { comercialização. }\end{array}$ \\
\hline
\end{tabular}


nicas de solução de problemas e aperfeiçoamento contínuo (tipo Kaizen) que requerem a participação dos funcionários e resulta em aprendizagem coletiva.

\section{Resultados alcançados}

O Quadro 2 sintetiza a análise do desempenho competitivo da indústria brasileira de transformação de plástico, considerando-se aquelas empresas alinhadas em cadeias produtivas e também aquelas que operam fora das cadeias.

\section{Principais resultados}

A indústria de transformação de plástico está ganhando importância estratégica na medida em que:

- as aplicações do plásticos se tornam cada vez mais numerosas e mais sofisticadas

- exige o desenvolvimento de conhecimento e competência específicas

- por sua vez requerem empresas dedicadas

- trabalhem ou não articuladas a cadeias produtivas.

A formação e o desenvolvimento da indústria brasileira de transformação de plástico está em relativo descompasso com essas tendências. Numa avaliação agregada, responde mal às demandas. Essa conclusão fica reforçada ao se considerar que as empresas da amostra foram indicadas por seus fornecedores e clientes como empresas destacadas na indústria.

A capacitação empresarial e gerencial, com algumas exceções precisa ser aperfeiçoada para poder trabalhar adequadamente em mercados cada vez mais internacionalizados e cada vez mais exi- gentes em termos de qualidade e inovações.

É relevante a informação de que são as empresa produtoras de resina as responsáveis pela inovação nas cadeias que nela se iniciam, com uma exceção recente: a indústria automobilística para a qual o plástico passou a se constituir um material estratégico. Por outro lado, no caso brasileiro, a constituição de cadeias produtivas está ocorrendo de maneira peculiar. No plano das empresas pode-se destacar a dificuldade de se estabelecer estratégias e comportamentos empresariais cooperativos e uma orientação programática de curto prazo. Com isto as condições para um alinhamento proativo ficam prejudicadas e, na prática, a formação de cadeias passa a depender de jogos de pressão e de força das empresas que comandam as cadeias produtiva. Nesta condições, estas têm muito mais poder de barganha do que se a empresas tivessem maior integração estratégica. Usando o conceito de custos de transação, parece não estar claro para as empresas locais os custo associados à desintegração e desconfianças que prevalecem na grande maioria das relações inter-empresariais. Mais do que isso, esse quadro inibe possíveis ganhos de sinergia entre os participantes, como por exemplo:

- relações transformadoras de plásticos - fabricantes de máquinas - Além da questão da criação de demanda, a relação entre as empresas transformadoras e as empresas fabricantes de máquinas é fundamental para a aprendizagem e a inovação tecnológica de ambos: os fabricantes do ponto de vista de aperfeiçoamento das máquinas e os transformadores do ponto de vista do fine tuning do processo produtivo. Na medida em que se confirme as previsões de entrada de novas empresas estrangeiras de transformação de plástico, a tendência é de se alterar ainda mais o perfil da demanda, que deve priorizar ainda mais a importação e induzir as empresas locais a representar empresas estrangeira, que podem também vir a produzir no país.

- relações transformadoras de plástico - fabricantes de moldes As empresas de transformação de plástico estão dando preferência a fornecedores de moldes estrangeiros por questões de preço e prazo (além do caso já discutido das empresas montadoras que assumem a posse dos moldes). Muito embora, no curto prazo essa decisão seja justificável, isto pode vir a configurar uma situação de maior vulnerabilidade para as empresas locais, na medida em que o molde está sendo considerado como um componente importante para o diferencial competitivo de uma empresa em termos de desempenho operacional. Ou seja, saber como projetar o molde dentro das mais modernas técnicas pode tornar vantagem competitiva nessa indústria. Ao mesmo tempo, a reestruturação das ferramentarias tem consequiências sobre o emprego de ferramenteiro que, como se sabe, é o mais qualificado entre os profissionais da indústria.

- relações transformadoras de plástico - produtores de resina Estas relações são, em muitos casos, conflituosas. As empresas de transformação de plástico que têm poder de barganha ou conseguem preços especiais, ou contornam o 
problema dos preços através de importação. As disputas que se observa não favorecem o processo de negociação que se faz necessário para o posicionamento das empresas nas cadeias produtivas. Em síntese, a maior parte das empresas está funcionando de maneira a sobreviver no "dia-a-dia", não tendo fôlego (em termos de recursos humanos e financeiro) para investir na capacitação de seus quadros.

Seguindo uma tradição na cultura empresarial brasileira, a ges- tão de recursos humanos, que por muito tempo era função de mais baixa prioridade, passa a ser considerada prioritária e estratégica. Mas a realização desse discurso tem sido difícil pela conjuntura pela qual passam as empresas. Parafraseando um dos mais reputados executivos de empresa da atualidade, o segredo da gestão é saber compatibilizar o planejamento de longo prazo com as ações de curto prazo, não tendo possibilidade e recursos para pensarem no longo prazo.

\section{Referências}

Gereffi, G (1994). Capitalism, development and global commodity chains. In Leslie Sklair (ed.), Capitalism and Development. London: Routledge

Nota: O estudo sobre a indústria de plásticos foi revisto e reanalisado no livro:

Fleury, A. e Fleury, M. T. (2000). "Estratégias empresariais e formação de competências: montando o quebra cabeças caleidoscópico da indústria brasileira”. São Paulo, Editora Atlas.

Matéria elaborada pelos professores Afonso Fleury da Escola Politécnica da USP e Maria Tereza Fleury da Faculdade de Economia e Administração da USP. 0 Prof. Fleury é atualmente professor titular do Departamento de Engenharia de Produção da Escola Politécnica da USP e presidente da Fundação Carlos Alberto Vanzolini, tendo feito seu curso de mestrado na Stanford University e doutorado na Escola Politécnica da USP 